Abstract ID 23 - International Journal of Hydrogen Energy

Abstract ID 23 - International Journal of Hydrogen Energy

\title{
Zeolite supported Pd electrocatalyst nanoparticle characterization
}

Jun $\mathrm{Yao}^{\mathrm{a}^{*}}$, Yufeng Yao

${ }^{\text {a }}$ School of Engineering, University of Lincoln, Brayford Pool, Lincoln LN6 7TS, UK

jyao@lincoln.ac.uk

${ }^{\mathrm{b}}$ Department of Engineering Design and Mathematics, University of the West of England,

Coldharbour Lane, Bristol BS16 1QY, UK, Yufeng.Yao@uwe.ac.uk

*Correspondent Author. Tel: +44 (0)1522 837 7919, Email: jyao@lincoln.ac.uk (J. Yao)

\section{Highlights:}

- Detail Pd cluster structure by the ex-situ Extended X-ray Adsorption Fine Structure (EXAFS) method.

- Evaluate $\mathrm{Pd} / \mathrm{Y}$-zeolite nanoparticle size under calcinations and reduction temperature.

- Measure Pd nanoparticle electrochemical activity in electrolyte solution.

- Discuss electrochemical reaction behaviour with respect to Pd particle size.

- $\quad$ Explore Pd particle location and Pd particle migration and electrochemical behaviour.

\section{$\underline{\text { Abstract }}$}

A laboratory made $1.5 \mathrm{wt} \%$ Palladium $(\mathrm{Pd})$ zeolite electrocatalyst is investigated using the Extended X-ray Adsorption Fine Structure (EXAFS) and Cyclic Voltammetry (CV) techniques to reveal Pd structure and resultant electrochemical performance. It was found that the 
Abstract ID 23 - International Journal of Hydrogen Energy

electrochemical activity of hydrogen charger transfer in the hydride region increased for electrocatalyst with large-size particles made at high temperature of $400{ }^{\circ} \mathrm{C}$, compared to those with small-size particles calcined and reduced at temperature below $360{ }^{\circ} \mathrm{C}$, at which no major discrepancies were observed between catalysts of different sizes. Furthermore, Pd particle location has played an important role to enhance electrocatalyst performance. The Pd atom tends to remain at small cages, i.e. zeolite sodalite cages or hexagonal prisms at calcinations and reduction temperatures below $360{ }^{\circ} \mathrm{C}$. When temperature increases to about $400{ }^{\circ} \mathrm{C}$, the majority $\mathrm{Pd}$ atoms tend to migrate from zeolite small cages to supercages and zeolite external structures with enhanced electrochemical performance.

Keywords: Pd nanoparticle mobility; Calcinations and reduction temperatures; Cyclic Voltammetry (CV); Ex-situ EXAFS; Electrochemical activity; Zeolite sodalite cages and hexagonal prisms.

\section{Introduction}

The hydrogen polymer electrolyte fuel cell (PEFC) has been extensively investigated over the past five decades, with most studies focused on electrochemical reactions including the hydrogen oxidation reaction (HOR) and oxygen reduction reaction (ORR) [1, 2]. While the Platinum (Pt) based electrocatalysts have been proved to be the best choice for HOR and ORR reactions due to their high activity and stability [2], the high $(\mathrm{Pt})$ price has limited its wider industry applications. This largely stimulates researchers to search for alternative electrocatalysts with comparable performance but at much reduced cost. The Palladium (Pd) as one of the Pt-group metals has attracted significant attentions, owing to its relatively good HOR and ORR activities [3], and much low cost (only about one third of that of Pt). In general, the Pd-based catalyst has shown lower catalytic activity than those Pt electrocatalysts, but it 
exhibits a high electrocatalytic activity for oxidation reaction using small organic molecules, e.g. methanol and ethanol due to a better resilience to $\mathrm{CO}$ poisoning [4]. Hence, Pd nanoparticle catalyst can be a potential good candidate as an electrocatalyst for fuel cell applications, if Pd catalytic activity and stability can be largely improved to be compatible with Pt electrochemical activity. This is the main motivation of this proposed study.

Recently, a lot of efforts have been made to focus on the development of carbon and graphene based Pd-nano electrocatalysts [5] using approaches such as surface modification, composition control [6], alloying [7] and spontaneous methods [8] for hydrogen fuel production in PEFCs. In addition, the 'support promotion' method is another approach employed to improve catalyst nanoparticle distribution for hydrogen fuel cell efficiency enhancement [2]. Zeolite is a type of porous amorphous material consisting of crystalline framework, formed by aluminosilicates structure comprised of $\mathrm{SiO}_{4}$ and $\mathrm{AlO}_{4}$ tetrahedral forms as the base units. These tetrahedral structures are interlinked with each other by sharing one oxygen atom. Each $\left[\mathrm{AlO}_{4}\right]^{-}$tetrahedron in the framework induces negative charges which can be compensated by a charge--balancing cations of $\mathrm{Na}^{+}$or $\mathrm{H}^{+}$ions situated in the zeolite channels or cavity. The extra framework of metal ions on zeolite active sites (also called Brфnsted acidic sites) are mobilized to take part in an ion exchange process with the desired metal ions. The ' $\mathrm{X}$ ' or ' $\mathrm{Y}$ ' type of zeolite channel structure with exemplary surface area and cation exchange capacity makes it a desirable platform for adsorption of different species to produce fine metal particle distribution. Moreover, the larger surface area and the pore structure of zeolite enable to absorb the electrolyte and electrochemical reaction species, which can lead to a suitable condition for electrochemical measurement during diffusion-controlled mass transfer process [9].

Zeolite catalytic performance can be modified by pre-exchanging with ions to give the desired form and then lock the exchangeable metal ions into the position by calcinations and reduction process with fine-tuned temperature control to further promote catalytic activity of 
metal particles [10]. For example, Spoto et al. investigated 4 wt $\%$ Pd loading on $\mathrm{NH}_{4}-\mathrm{Na}-\mathrm{Y}$ zeolite exchanged with aqueous solution of $\left[\mathrm{Pd}\left(\mathrm{NH}_{3}\right)_{4}\right]\left(\mathrm{NO}_{3}\right)_{2}$ under calcinations at $200{ }^{\circ} \mathrm{C}$ and reduction at $300{ }^{\circ} \mathrm{C}$, respectively. The hydrogen atoms transiting through silicate rings are the possible mechanisms for hydrogen transport to and from the sodalite - cages due to hydrogen diffusion in active form through zeolite framework by spill-over effects that hydrogen can be adsorbed by $\mathrm{Pd}[11]$. The proton is able to migrate to zeolite neighboring rings, facilitating the mobility of hydrogen atoms in the silicate framework. The penetration probability of hydrogen within sodalite cage and hexagonal prism can be further enhanced by the presence of $\mathrm{Pd}$ catalytic active site on zeolite. The large-size Pd nanoparticle is found to locate at the exterior of zeolite surface due to the migration of Pd atoms from zeolite internal structure to the external surface during reduction process [11]. Alternatively, the atomic hydrogen can diffuse into the zeolite sodalite cages by penetrating from hexagonal openings of the zeolite framework. Homeyer and Sachtler [12] have reported that $\mathrm{Pd}\left(\mathrm{NH}_{3}\right)_{\mathrm{x}}{ }^{2+}$ ions release into zeolite supercages at calcinations temperature of $250{ }^{\circ} \mathrm{C}$. The oxidation of $\mathrm{Pd}\left(\mathrm{NH}_{3}\right)_{4}{ }^{2+}$ ions were observed to produce $\mathrm{Pd}\left(\mathrm{NH}_{3}\right)_{2}{ }^{2+}$ ions in supercages and $\mathrm{Pd}\left(\mathrm{NH}_{3}\right)^{2+}$ in sodalite cages [13]. Further temperature increase was found to result in producing $\mathrm{Pd}^{2+}$ ions at calcinations temperature over $300{ }^{\circ} \mathrm{C}$. The $\mathrm{Pd}^{2+}$ ions were found to have a high mobility, migrating from zeolite external surface and supercages into zeolite small cages i.e. sodalite cages or hexagonal prism. Most $\mathrm{Pd}^{2+}$ ions were forced into sodalite cages at the calcinations temperature up to $500{ }^{\circ} \mathrm{C}$.

The reduction process has shown that $\mathrm{Pd}$ atom is more favorable to remain in the zeolite supercages than the sodalite and hexagonal prism [11]. Bergeret et al. [14] and Kleine et al. [15] have found that the reduction can result in agglomeration of $\mathrm{Pd}$ atoms in the supercages with primary particle size less than $7 \AA$. These particles could extend over several cages at high temperature condition. Pd species were observed to migrate back into zeolite supercages at reduction temperature of $360{ }^{\circ} \mathrm{C}$. Moreover, the mobility of $\mathrm{Pd}$ might be contributed by the 
restoration of zeolite active sites (i.e. Brpnsted acidic sites) via $\mathrm{H}_{2}$ reduction [16]. $\mathrm{H}_{2}$ can have affinity with proton to induce a ligand displacement with the $-\mathrm{OH}$ groups interacted to oxygen atoms in the sodalite cages and form the hydrogen bonded complex [11].

In a previous study, the in-situ EXAFS data analysis of Pd nanoparticle structure on $\mathrm{Y}$ zeolite in an electrochemical environment has predicted a first shell Pd-Pd distance of $2.73 \AA$ with respect to a Pd first shell coordination number of 12 which give rise to an average radius of metal particle greater than $15 \AA$ [11]. However, the average of Pd particle size is still smaller on zeolite than on carbon and those coated on microcellular graphitic carbon where Pd particles can be between $2.7 \mathrm{~nm}-65.2 \mathrm{~nm}$ and $6.6 \mathrm{~nm}-30.3 \mathrm{~nm}$, respectively [17].

Pd also has a capability of bulk incorporation of hydrogen that can lead to the high solubility and mobility of hydrogen in Pd. This might be associated to the diffusion of atomic hydrogen produced by the disassociation of the $\mathrm{H}_{2}$ molecule on the $\mathrm{Pd}$ metal particles due to hydrogen spillover ability on Pd within zeolite internal structure especially sodalite cages. Subsequently, the Pd sample activation procedure can be important to control the atomic hydrogen spillover efficiency on Pd [11, 18]. Recently, zeolite supported Pd material has attracted a significant interest for its applications to enhance the fuel cell efficiency.

Generally, the pathway of hydrogen oxidation reaction (HOR) can include three important steps that might occur either via Volmer-Fafel or Volmer-Heyrovsky reaction process or both $[2,19,20]$. In acid electrolyte solution, the activity of HOR on Pd or Pt surface follows a very identical trend of hydrogen evaluation reaction that follows three reaction steps, in which the first step involves the Volmer reaction to receive an electron by a proton, leading to an intermediate hydrogen atom to be adsorbed at the active sites [21], whilst the second step was given by Heyrovsky or Tafel reaction, in which hydrogen was produced by two adsorbed hydrogen atoms on active sites of electrocatalyst [2]. Moreover, the Pd was found to exhibit the lower kinetics of hydrogen evolution reaction (HER) than Pt. Thus, the different approaches [5, 
Abstract ID 23 - International Journal of Hydrogen Energy

$6,7,8]$ have been explored to develop the cost effective Pd electrocatalyst system, such as, nanocomposites [6] supported on different porous medium materials.

The study presented in this paper will focus on the investigation of Pd sample activating procedure that might affect the electrochemical performance of hydrogen oxidation and oxygen reduction process on $\mathrm{Pd}$ active sites in the electrolyte solution. The electrocatalytic activity of $1.5 \mathrm{wt} \% \mathrm{Pd}$ on zeolite made by ion exchange method under various calcinations and reduction temperatures was investigated using Cyclic Voltammetry (CV) technique. Pd particle size and its dispersion on zeolite will be characterized by the ex-situ extended X-ray adsorption fine structure (EXAFS) using pallet made by Pd zeolite catalyst and boron nitride. The study will contribute to the well understanding of Pd electrocatalyst efficiency enhanced by hydrothermal process under calcinations and reduction temperature control.

\section{Experimental}

\subsection{Preparation of Pd/Y zeolite electrocatalysts}

The ion exchange method has been employed to achieve $1.5 \mathrm{wt} \% \mathrm{Pd}$ loading on Y zeolite using $\left(\mathrm{NH}_{3}\right)_{4} \mathrm{PdCl}_{4}[7,19,22]$. In this process, the $\left[\mathrm{Pd}\left(\mathrm{NH}_{3}\right)_{4}\right]^{4+}$ ligand was ion exchanged with $\mathrm{Na}^{+}$ions situated on the alumina tetrahedral arrangement of $\left[\mathrm{AlO}_{4}\right]^{-}$ions that led to a high dispersion of $\mathrm{Pd}$ on zeolite with uniform distributions $[22,23]$. Each positive $\left[\mathrm{Pd}\left(\mathrm{NH}_{3}\right)_{4}\right]^{4+}$ ion can interact with four negative charged $\left[\mathrm{AlO}_{4}\right]^{-}$ions to introduce a charge balance. Then, further calcinations reaction can induce a $\mathrm{Pd}^{4+}$ ion which bridges with four $\left[\mathrm{AlO}_{4}\right]^{-}$ions after decomposition of ammonia ligand.

The ion exchange process was carried out at PH7 in a neutral solution. An appreciated quantity of $\left(\mathrm{NH}_{3}\right)_{4} \mathrm{PdCl}_{4}$ was introduced in $200 \mathrm{ml}$ of triply distilled water to produce a $\mathrm{Pd}$ concentration of $0.004 \mathrm{~mol} \mathrm{dm}{ }^{-3}$. The Pd salt was dissolved uniformly in an ultrasonic bath at ambient room temperature. The process of $\left[\mathrm{Pd}\left(\mathrm{NH}_{3}\right)_{4}\right]^{4+}$ ions exchange with zeolite was taken 
Abstract ID 23 - International Journal of Hydrogen Energy

place using a water jacketed reaction with water cycled around at $70{ }^{\circ} \mathrm{C}$, in which $\mathrm{Y}$ zeolite powder was dispersed at a concentration of $1 \mathrm{~g}$ per $100 \mathrm{ml}$ of triply distilled water. The Pd salt solution was then pumped into the reactor at a flow rate of $0.1 \mathrm{ml} / \mathrm{min}$. The resultant $\mathrm{Pd} / \mathrm{Y}$ zeolite samples were washed with a sufficient amount of triply distilled water until no $\mathrm{Cl}^{-}$ions detected by $1 \mathrm{~N} \mathrm{AgNO}_{3}$ solution. The completion of Pd complex ion exchange was confirmed by UV spectrum.

\subsection{Synthesis of $1.5 \mathrm{wt} \%$ Pd zeolite electrocatalyst}

$1.5 \mathrm{wt} \% \mathrm{Pd} / \mathrm{Y}$ zeolite electrocatalysts were made by calcinations and reduction processes to remove Pd coordinate ligand. The $\left[\mathrm{Pd}\left(\mathrm{NH}_{3}\right)_{4}\right]^{4+}$ salt loaded $\mathrm{Y}$ zeolite samples were purged with argon gas at $150{ }^{\circ} \mathrm{C}$ to dry out the water moisture in a fluidized reactor. The calcinations of $\left[\mathrm{Pd}\left(\mathrm{NH}_{3}\right)_{4}\right]^{4+}$ salt/Y zeolite samples were carried out at $250{ }^{\circ} \mathrm{C}, 350{ }^{\circ} \mathrm{C}$ and $400{ }^{\circ} \mathrm{C}$, respectively, in $\mathrm{O}_{2}$ gas phase at a flow rate of $200 \mathrm{ml} / \mathrm{min}$, and then followed by reduction in a $5 \% \mathrm{H}_{2} / 95 \% \mathrm{~N}_{2}$ gas mixture at $360{ }^{\circ} \mathrm{C}$ or $400{ }^{\circ} \mathrm{C}$ to produce a fine distribution of $\mathrm{Pd}$ particles on zeolite.

Figure 1 illustrates the Pd migration pathways through zeolite structure under calcinations and reduction temperature control. The ion exchange process is to locate $\left[\mathrm{Pd}\left(\mathrm{NH}_{3}\right)_{4}\right]^{4+}$ ligand on zeolite exterior surface and in supercages. The ammonia ligands start to decompose at 250 ${ }^{\circ} \mathrm{C}[13]$ and produce $\left[\mathrm{Pd}\left(\mathrm{NH}_{3}\right)_{2}\right]^{2+}$ (see formula 1 in Fig. 1). The $\mathrm{Pd}^{2+}$ ions can migrate through zeolite channels and then further extend to zeolite small cages, i.e. sodalite cages and hexagonal prisms at calcinations temperature of $300{ }^{\circ} \mathrm{C}$ (see formula 2 in Fig. 1). Continuous increase of calcinations and reduction temperatures up to $350{ }^{\circ} \mathrm{C}$ and $360{ }^{\circ} \mathrm{C}$ respectively might force $\mathrm{Pd}$ atoms to migrate back into zeolite sodalite cages or zeolite supercages (see formula 3 in Fig. 1). Pd atoms can move back from zeolite small cages to supercages and zeolite external surface at calcinations and reduction temperature of $400{ }^{\circ} \mathrm{C}$ (see formula 3 in Fig. 1). 


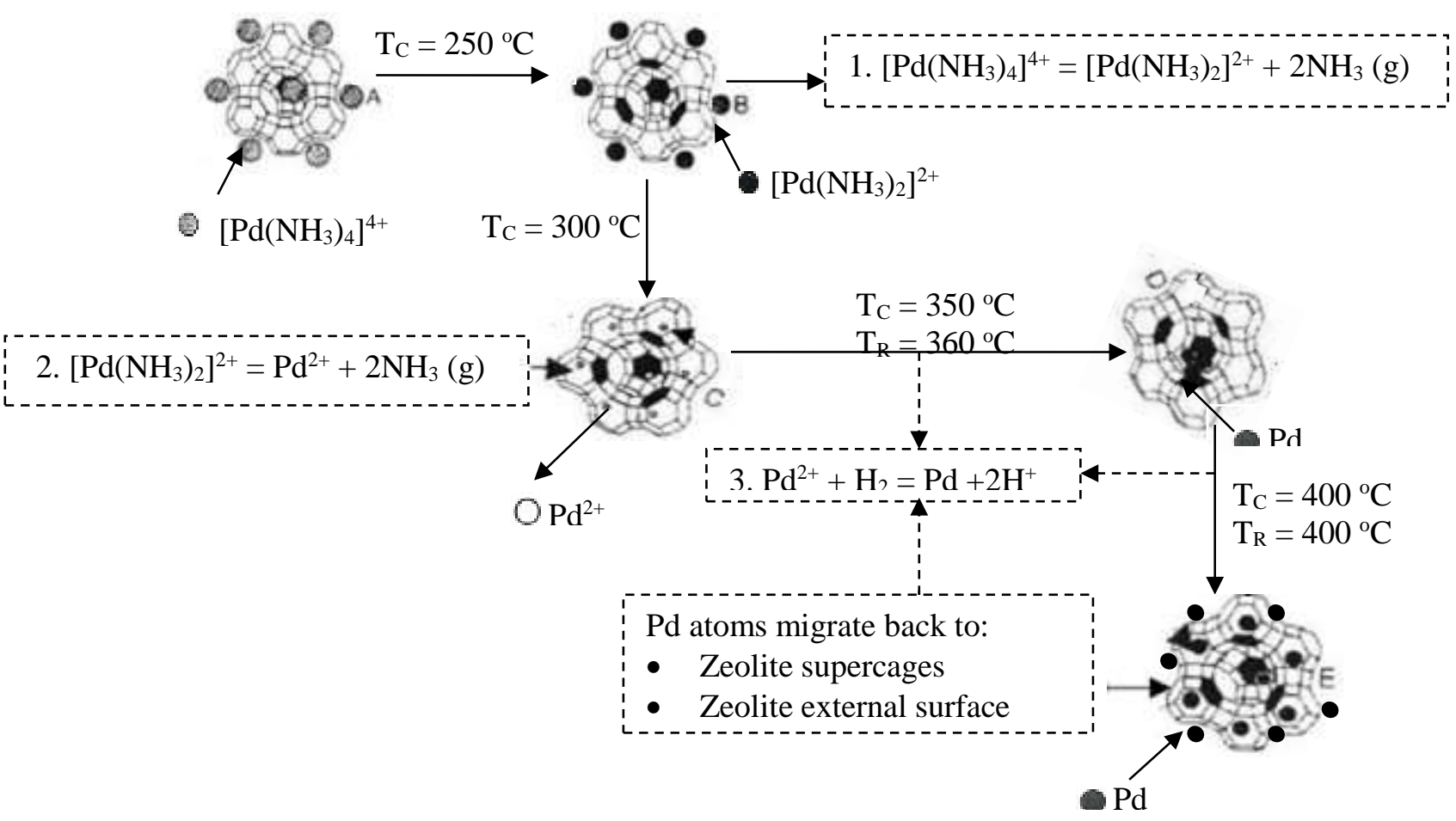

Figure 1. A schematic diagram depicts Pd migration controlled by calcinations (denoted as ' $\mathrm{C}$ ') and reduction (denoted as ' $R$ ') process.

The following equation (1) prescribes an overall chemical reaction of Pd ligand by calcinations and reduction process:

$$
\left[\mathrm{Pd}\left(\mathrm{NH}_{3}\right)_{4}\right]^{4+}+\mathrm{O}_{2}(\text { gas })+2 \mathrm{H}_{2}(\text { gas })=4 \mathrm{NH}_{3}(\text { gas })+2 \mathrm{H}_{2} \mathrm{O}+\mathrm{Pd}
$$

\subsection{Electrochemical cell and cyclic voltammetry (CV)}

A typical $9 \mathrm{~cm}^{2}$ electrode sheet was made of $1.5 \mathrm{wt} \%$ Pd loading on zeolite electrocatalyst mixed with XC-72R carbon powder (untreated) mixture and $15 \mathrm{wt} \%$ Nafion ${ }^{@}$ solution (from Aldrich) as a binding agent. A solidification process was then taken place by hot pressing the resultant paste on carbon paper (E-TEK TGHP-90). A $2.5 \mathrm{~cm}^{2}$ diameter disc electrode was trimmed for a standard CV measurement that was performed using a glass-jacket 
Abstract ID 23 - International Journal of Hydrogen Energy

electrochemical cell, consisting of a zeolite supported $\mathrm{Pd}$ working electrode, $\mathrm{Hg} / \mathrm{Hg}_{2} \mathrm{SO}_{4}$ Mercury/Mercuries Sulphate (MMS) reference electrode and a Pd gauze counter electrode. The electrolyte was $2.5 \mathrm{~mol} \mathrm{dm}{ }^{-3}$ sulfuric acid $\left(\mathrm{H}_{2} \mathrm{SO}_{4}\right)$ solution and the $\mathrm{CV}$ was measured at a scan rate of $1 \mathrm{mV} \mathrm{s}^{-1}$ in a potential region of $-0.675 \mathrm{~V}$ to $0.4 \mathrm{~V}$ for $1.5 \mathrm{wt} \%$ Pd loading on zeolite samples calcined at $250{ }^{\circ} \mathrm{C}$ and reduced at $360{ }^{\circ} \mathrm{C}$ (denoted as $15 \mathrm{Pdanc} 25 \mathrm{r} 36$ ), calcined at 350 ${ }^{\circ} \mathrm{C}$ and reduced at $360{ }^{\circ} \mathrm{C}$ (denoted as $15 \mathrm{Pdanc} 35 \mathrm{r} 36$ ) and calcined and reduced at $400{ }^{\circ} \mathrm{C}$ (denoted as 15Pdancr40), respectively, in which no electrolyte decomposition was detected.

\subsection{The Ex-situ Extended X-ray Adsorption Fine Structure (EXAFS) Measurement}

$\mathrm{Pd} / \mathrm{Y}$ zeolite electrocatalysts were characterized by the ex-situ extended X-ray adsorption fine structure (EXAFS) measurement technique using a Synchrotron Radiation Source (SRS) at STFC Daresbury National Laboratory [7]. The wiggler beam line was operated at $2 \mathrm{GeV}$ and $100 \mathrm{~mA}$. Those high order harmonics that might affect the amplitude of EXAFS were removed using a double-crystal Si220 monochromator. The EXAFS data was then collected at the Pd K edge using a pellet placed in air. The pellet was made by $1.5 \mathrm{wt} \% \mathrm{Pd} / \mathrm{Y}$ zeolite catalyst powder mixed with boron nitride to give a Pd loading of $0.73 \mathrm{mg} \mathrm{cm}^{-2}$. A Pd foil was used as a reference sample for EXAFS data collection. The resultant EXAFS data was later analyzed using in-house software EXCURV 98, where the inter-atomic distance, atom number and the type of backscattering neighbors were determined by a method proposed by Abruna [24].

\section{Results and Discussion}

\subsection{The ex-situ extended X-ray adsorption fine structure (EXAFS) measurement}

Pd particle size and distribution for $1.5 \mathrm{wt} \% \mathrm{Pd}$ loading on zeolite were investigated using the ex-situ EXAFS technique. Figure 2, figure 3 and figure 4 display the EXAFS Chi data and 
Abstract ID 23 - International Journal of Hydrogen Energy

their Fourier transform fitting results using the ex-situ EXAFS measurement. The EXAFS data were collected at the Pd K edge in air. The fitted data are presented in tables 1, 2 and 3. The Chi data for catalyst samples 15Pdanc25r36 and 15Pdancr40 were valid over the range of wave vector from $2 \AA^{-1}$ to $18 \AA^{-1}$, and for catalyst sample 15 Pdanc 35 r 36 , Chi data were up to $17 \AA^{-1}$. A data scattering was observed in Chi spectrum at a slightly high noise level after $14 \AA^{-1}$. The EXAFS data was subsequently fitted up to 3 shells with respect to a goodness fitting value ( $\mathrm{R}_{\text {exafs }}$ ) of $40 \%$ representing an acceptable data fitting quality. The curve fitting (shown in dotted symbols) matches well against the raw data (shown in solid lines). The shells $1 \& 2 \mathrm{Pd}-\mathrm{Pd}$ coordination numbers were predicted at 5.2 and 2.05 for catalyst 15Pdanc25r36 (table 1), 4.25 and 3.22 for catalyst $15 \mathrm{Pdanc} 35 \mathrm{r} 36$ (table 2), and 5.77 and 2.22 for catalyst $15 \mathrm{Pdancr} 40$ (table 3), respectively. The Pd-Pd binding distance was determined at $2.74 \AA$, indicating that Pd atom had metallic property in nature. A Pd-O shell was further added to improve data fitting quality for all three catalyst samples. The Pd-O distance was predicted at $2.01 \AA$ for catalyst samples 15Pdanc35r36 (table 2) and 15Pdancr40 (table 3) and $2.02 \AA$ for catalyst sample 15Pdanc25r36 (table 1), respectively. The presence of $\mathrm{O}$ neighboring atom indicates the oxidation of $\mathrm{Pd}$ to form Pd-O shell.

The Pd cluster size and geometry might be estimated using the first (or nearest) neighbor mean coordination number $\overline{N_{1}}$ of atoms in a cluster using method suggested by Benfield [25]. An icosahedra cluster is adopted to estimate the Pd cluster edge length using $\overline{N_{1}}$, due to $\mathrm{Pd}$ metallic feature in nature. An average theoretical first (or nearest) neighbor mean coordination number and a total number of atoms in a cluster was estimated at 6.45 and 13, using equations (2) and (3) [25]. The Pd-Pd first shell coordination number estimated by EXAFS is slightly lower than those given by Benfield theory [25]. On average the Pd atoms are estimated at 11, 10 and 12, respectively based on EXAFS data analysis, which results in the following order of Pd particle size in radius: 15 Pdancr40 at $1.0 \mathrm{~nm}>15$ Pdanc $25 \mathrm{r} 36$ at $0.9 \mathrm{~nm}>15$ Pdanc $35 \mathrm{r} 36$ at 
$0.8 \mathrm{~nm}$. The EXAFS results imply that Pd particle size increases with the increase of calcinations and reduction temperatures. The larger particle size is usually correspondent to a low Pd active surface area based on per gram of metal. Thus, the expected electrochemical activity of charger transfer under the features of the hydride peak would be in an order of 15 Pdancr40 < 15Pdanc25r36 < 15Pdanc35r36, only if the calcinations and reduction temperature has solely effect on the particle size. However, this is not a type of trend being observed in CV measurement by determining charger transfer in hydride region. Therefore, the location of the metal particle on zeolite must also be taken into a consideration.

Unlike Pt, $\mathrm{Pd}$ is more capable to mobile from zeolite small cages to supercages and zeolite external surface under high calcinations and reduction temperature, due to its 'd' electron configuration [26] that can be altered with the change of Pd electronic and geometric structure [27]. The valence electrons on $\mathrm{Pd}$ are in the form of $4 \mathrm{~d}$ orbital shape, whilst they are in the $5 \mathrm{~d}$ orbital shape on $\mathrm{Pt} . \mathrm{Pd}^{2+}$ has a greater charge density than $\mathrm{Pt}^{2+}$. This will lead to the increase of the mobility of Pd. By controlling the calcinations and reduction temperature, $\mathrm{Pd}$ particle can be enriched in the zeolite supercages and zeolite external surface. Pd particles in these locations are more accessible to the protons in the electrolyte solution. In addition, Pd particles on the zeolite external surface might have a better electronic contact with the carbon support [7].

$$
\begin{aligned}
& \overline{N_{1}}(i \cos )=6\left[(m-1)\left(2 m^{2}-25 m+12\right)\right] /\left[(2 m-1)\left(5 m^{2}-5 m+3\right)\right] \\
& N_{\text {total }}=(1 / 3)(2 m-1)\left(5 m^{2}-5 m+3\right)
\end{aligned}
$$


Abstract ID 23 - International Journal of Hydrogen Energy

Table 1. The ex-situ EXAFS data fitting results for data collected at the Pd K edge at ambient room temperature for catalyst sample 15Pdanc $25 \mathrm{r} 36$

\begin{tabular}{|l|c|c|c|}
\hline 15Pdanc25r36 & $\mathrm{N}$ & $2 \sigma^{2} / \AA^{2}$ & $\mathrm{R} / \AA$ \\
\hline Shell 1 O & $0.95 \pm 0.09$ & $0.0049 \pm 0.0012$ & $2.02 \pm 0.006$ \\
\hline Shell 2 Pd & $5.20 \pm 0.62$ & $0.0141 \pm 0.0003$ & $2.74 \pm 0.003$ \\
\hline Shell 3 Pd & $2.05 \pm 0.54$ & $0.0125 \pm 0.0032$ & $3.41 \pm 0.017$ \\
\hline
\end{tabular}
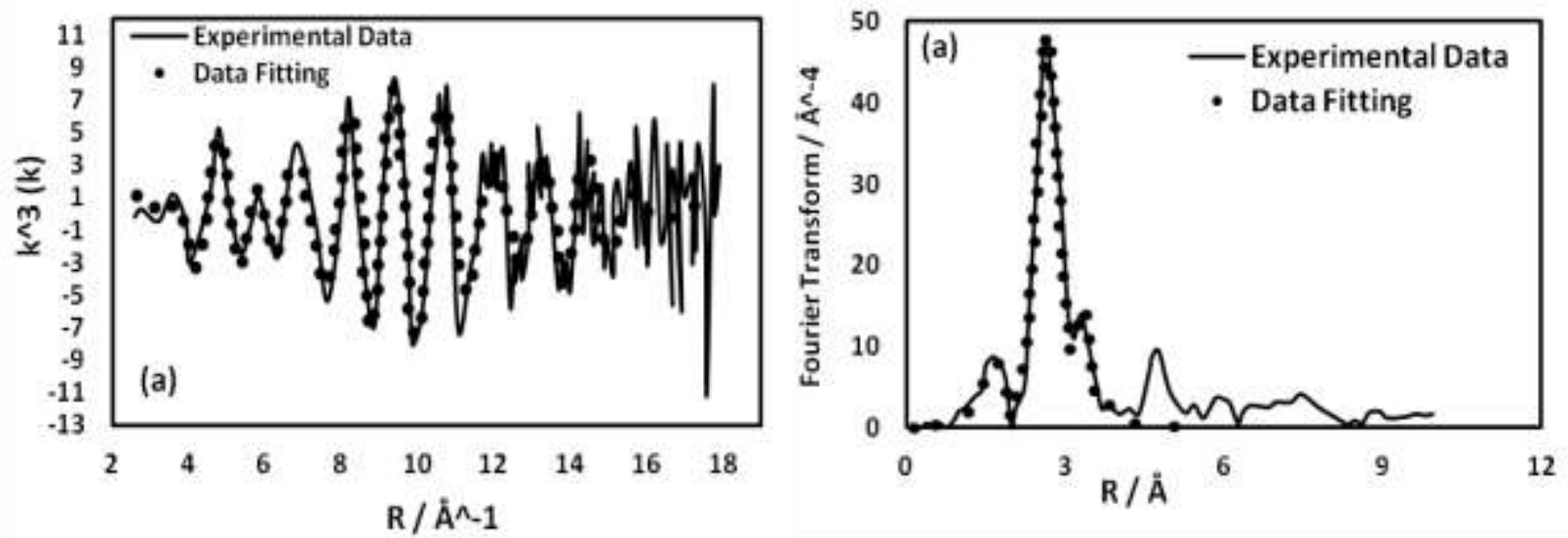

Figure 2. The ex-situ EXAFS Chi data and Fourier transforms and their fitting results for catalyst sample 15 Pdanc25r36, phase corrected. The data were collected at ambient room temperature in air. The solid lines represent the experimental data, and the dotted symbols represent the fitted data. 
Abstract ID 23 - International Journal of Hydrogen Energy

Table 2. The ex-situ EXAFS data fitting results for data collected at the Pd K edge at ambient room temperature for catalyst sample 15Pdanc35r36

\begin{tabular}{|l|c|c|c|}
\hline 15Pdanc35r36 & $\mathrm{N}$ & $2 \sigma^{2} / \AA^{2}$ & $\mathrm{R} / \AA$ \\
\hline Shell 1 O & $1.45 \pm 0.25$ & $0.0063 \pm 0.0023$ & $2.02 \pm 0.006$ \\
\hline Shell 2 Pd & $4.25 \pm 0.28$ & $0.0135 \pm 0.0006$ & $2.74 \pm 0.003$ \\
\hline Shell 3 Pd & $3.22 \pm 0.57$ & $0.0147 \pm 0.0016$ & $3.42 \pm 0.010$ \\
\hline
\end{tabular}
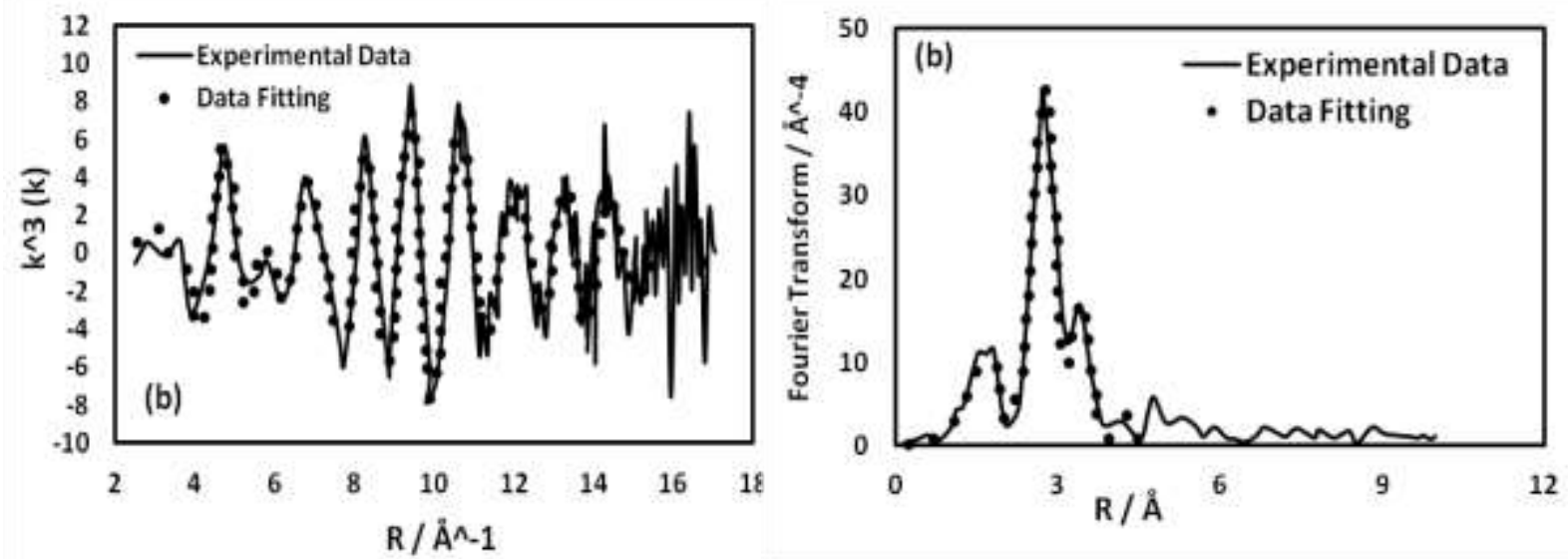

Figure 3. The ex-situ EXAFS Chi data and Fourier transforms and their fitting results for catalyst sample 15Pdanc35r36, phase corrected. The data were collected at ambient room temperature in air. The solid lines represent the experimental data, and the dotted symbols represent the fitted data. 
Abstract ID 23 - International Journal of Hydrogen Energy

Table 3. The ex-situ EXAFS data fitting results for data collected at the Pd K edge at ambient room temperature for catalyst sample $15 \mathrm{Pdancr} 40$

\begin{tabular}{|l|c|c|c|}
\hline 15Pdancr40 & $\mathrm{N}$ & $2 \sigma^{2} / \AA^{2}$ & $\mathrm{R} / \AA$ \\
\hline Shell 1 O & $1.10 \pm 0.30$ & $0.0072 \pm 0.0038$ & $2.01 \pm 0.018$ \\
\hline Shell 2 Pd & $5.77 \pm 0.33$ & $0.0141 \pm 0.0006$ & $2.74 \pm 0.005$ \\
\hline Shell 3 Pd & $2.22 \pm 1.01$ & $0.0200 \pm 0.0053$ & $3.39 \pm 0.013$ \\
\hline
\end{tabular}
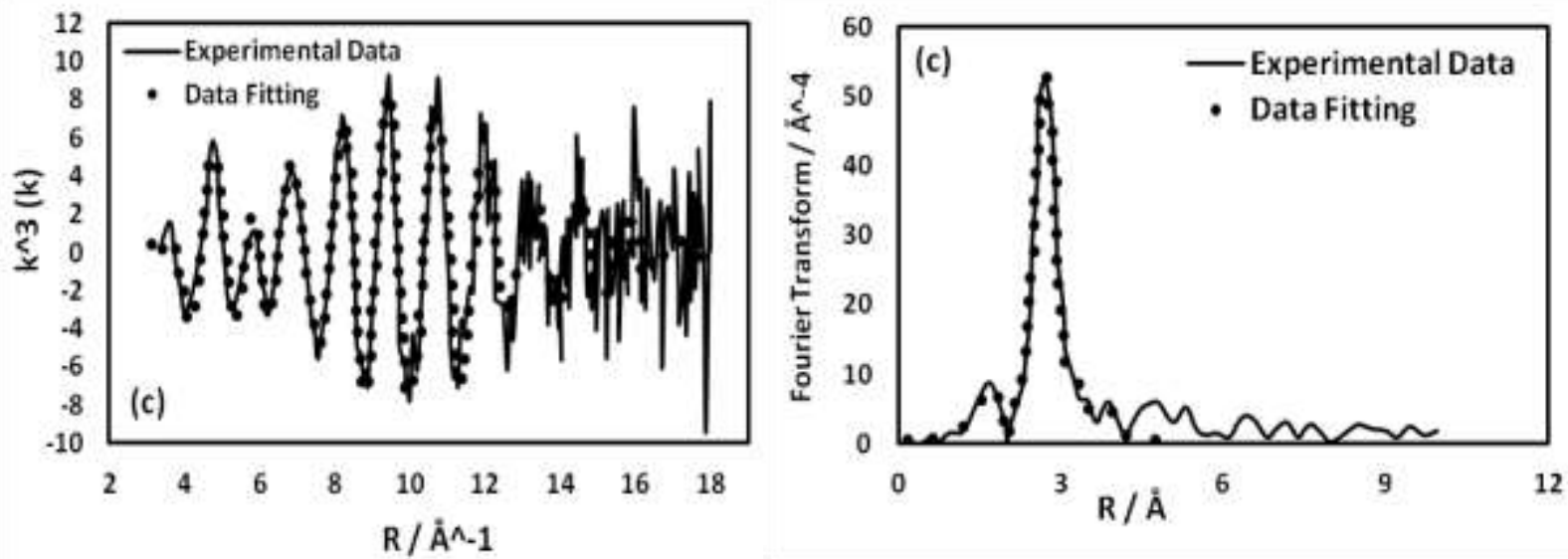

Figure 4. The ex-situ EXAFS Chi data and Fourier transforms and their fitting results for catalyst sample 15Pdancr40, phase corrected. The data were collected at ambient room temperature in air. The solid lines represent the experimental data, and the dotted symbols represent the fitted data.

\subsection{Cyclic Voltammetry (CV) Measurement}

The total accessible electrochemically active Pd surface area of electrode was measured in $2.5 \mathrm{~mol} \mathrm{dm}{ }^{-3}$ sulfuric acid $\left(\mathrm{H}_{2} \mathrm{SO}_{4}\right)$ solution, corresponding to catalyst samples 15 Pdanc $25 \mathrm{r} 36$, 15Pdanc35r36 and 15Pdancr40. Figure 5 displays a diagram of CV measurement using $1.5 \mathrm{wt} \%$ 
Abstract ID 23 - International Journal of Hydrogen Energy

Pd on XC-72R Nafion ${ }^{\circledR}$ bound working electrode made by a commercial catalyst of $40 \mathrm{wt} \% \mathrm{Pd}$ on XC-72R carbon mixed with extra XC-72R carbon powder (denoted as 15PdXC-72R) [28]. The two distinguished regions are identified and they are likely associated with the hydrogen adsorption, evaluation, hydrogen desorption and the re-oxidation peaks, respectively. This may be contributed by the morphology of Pd electrocatalyst [29]. A small peak 'A' is detected at $0.59 \mathrm{~V}$, which is correspondent to hydrogen adsorption on $\mathrm{Pd}$ active site. The hydrogen evolution (i.e. the peak ' $\mathrm{B}$ ') is observed at $-0.689 \mathrm{~V}$, and a double layer (DL) current density is measured between $-0.18 \mathrm{~V}$ and $-0.420 \mathrm{~V}$ in the cathodic sweep and from $0.18 \mathrm{~V}$ to $-0.4 \mathrm{~V}$ in the anodic sweeps, respectively. The hydrogen re-oxidation represented by the peak ' $C$ ' is determined at $-0.626 \mathrm{~V}$ on the anodic sweep and the second peak ' $\mathrm{D}$ ' at $-0.564 \mathrm{~V}$ is attributed to hydrogen desorption. The increase of current density from $0.226 \mathrm{~V}$ to $0.4 \mathrm{~V}$ is due to the formation of $\mathrm{Pd}$ oxide $(\mathrm{PdO})$ on $\mathrm{Pd}$ surface. A peak ' $\mathrm{E}$ ' predicted at $0.0656 \mathrm{~V}$ interprets the striping of $\mathrm{O}$ formed on $\mathrm{Pd}$ surface.

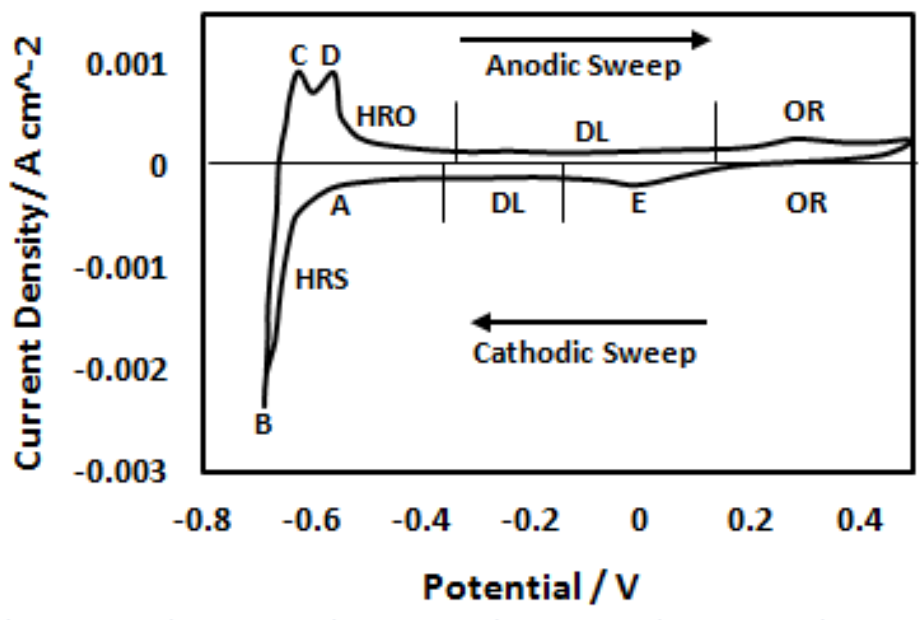

Figure 5. Steady State Cyclic Voltammogram (CV) measurement using 1.5 wt\% Pd on XC72R carbon powder Nafion ${ }^{\circledR}$ bound working electrode made by a commercial $40 \mathrm{wt} \% \mathrm{Pd}$ on $\mathrm{XC}-72 \mathrm{R}$ carbon electrocatalyst mixed with extra carbon powder (denoted as $15 \mathrm{PdXC}-72 \mathrm{R}$ ), 
Abstract ID 23 - International Journal of Hydrogen Energy

scanned at $1 \mathrm{mV} \mathrm{s}^{-1}$ in $2.5 \mathrm{~mol} \mathrm{dm}^{-3} \mathrm{H}_{2} \mathrm{SO}_{4}$ at the potential region of $-0.675 \mathrm{~V}$ to $0.4 \mathrm{~V}$ vs MMS reference electrode [28].

The electrochemical activity of Pd on zeolite was determined using a Nafion ${ }^{\circledR}$ bound Pd zeolite electrode fabricated by 1.5 wt $\%$ Pd loading on zeolite with extra XC-72R carbon power. Figure 6 has shown $\mathrm{CV}$ comparisons of electrochemical performance for $1.5 \mathrm{wt} \% \mathrm{Pd}$ zeolite samples made by calcinations and reduction process at different temperatures. The strong current density change was detected using electrode made by catalyst sample 15 Pdancr40 calcined and reduced at $400{ }^{\circ} \mathrm{C}$ in hydride region, where two distinguished peaks for weakly or strongly hydrogen desorption were captured at $-0.607 \mathrm{~V}$ and $-0.631 \mathrm{~V}$ in the anodic sweep. The peak tendency measured for catalyst sample 15 Pancr40 is very identical to that measured by catalyst sample $15 \mathrm{PdXC}-72 \mathrm{R}$. The current density of hydrogen desorption has seen a smaller increase for catalyst sample 15Pdanc35r36 than catalyst 15Pdanc25r36 in hydrogen adsorption and desorption regions, respectively, where a single hydrogen desorption peak is observed for both catalysts. There is no second hydrogen desorption peak captured in the hydride region, which implies these two hydrogen desorption peaks having a very similar energy level on Pd active sites. The current density increase in the hydride region follows an order of 15Pdancr40 > 15Pdanc35r36 > 15Pdanc25r36 > 15PdXC-72R. A similar tendency was detected in the oxygen oxidation and reduction region for all the four samples. The CV measurement indicates that the calcinations and reduction temperature increasing up to $400{ }^{\circ} \mathrm{C}$ enables the improvement of Pd electrocatalytic activity in an electrochemical environment. The similar peak areas captured in the hydride region for catalyst samples 15 Pdanc25r36 and 15Pdanc35r36 indicate that Pd particle has a very similar location in the structure of these two samples. The calcinations and reduction temperature has played a critical role to mobile the Pd atoms through the zeolite channel and cages. The Pd atoms can also migrate out from zeolite 
Abstract ID 23 - International Journal of Hydrogen Energy

hexagonal prisms to sodalite cages at the calcinations temperature of $350{ }^{\circ} \mathrm{C}$. The mobility of Pd particles from zeolite small cages to the supercages and zeolite external surface are more pronounced by high calcinations and reduction temperature at $400{ }^{\circ} \mathrm{C}$. This has resulted in the increase of the Pd active surface areas. Furthermore, the restoration of zeolite active sites (i.e. Br申nsted acidic sites) under hydrogen reduction process might have enhanced the migration of Pd atoms between the zeolite channels and cages [16].

Previously, the in-situ EXAFS data analysis to determine Pd particle structure in the hydride region via electrode made by catalyst samples of 15Pdanc35r36 has depicted a Pd-Pd distance of $2.83 \AA$ at $-0.675 \mathrm{~V}$ and $2.80 \AA$ at $-0.65 \mathrm{~V}$ which has seen a significant increase whereas compared to a metallic Pd-Pd distance of $2.74 \AA$ (see table 4) [28]. This increase corresponding to Pd distance might be due to hydrogen adsorbed on Pd surface or forming Pd hydride phases such as $\beta$-PdH or $\alpha-\mathrm{PdH}$ on Pd particle through 'spillover' of hydrogen atom on zeolite channel or surface conductance. The $\beta$-PdH associated with a direct hydrogen adsorption reaction between electrode surface and sub-surface might be decomposed to $\alpha$-PdH, due to the migration of hydrogen atom from a nearer surface of Pd hydride phase to the center of Pd particle. The Pd-Pd atom binding distance was predicted at $2.74 \AA$ at $-0.5 \mathrm{~V}$ and $2.73 \AA$ at $0.5 \mathrm{~V}$ which implies the Pd particle presenting more metallic features in nature. The $\mathrm{Pd}$ particle size tends to be large at more negative potential in the hydride region as indicated by the Pd first shell coordination number (see table 4), and this might be directly associated with the formation of $\beta-\mathrm{PdH}$ and $\alpha-\mathrm{PdH}$ hydride phase, resulting in a long $\mathrm{Pd}-\mathrm{Pd}$ distance in comparison to the Pd-Pd distance predicted for same catalyst samples in atmosphere condition. 
Abstract ID 23 - International Journal of Hydrogen Energy

Table 4. The in-situ EXAFS data fitted at the Pd K edge in hydride region at the potential of $-0.675 \mathrm{~V},-0.65 \mathrm{~V},-0.5 \mathrm{~V}$ and $+0.5 \mathrm{~V}$ via MMS reference electrode [28].

\begin{tabular}{|c|c|c|}
\hline $\begin{array}{c}\text { Shell 1_Pd / } \\
\text { Potential (V) }\end{array}$ & N & R/ $\AA$ \\
\hline$-0.675 \mathrm{~V}$ & $7.86 \pm 0.46$ & $2.83 \pm 0.005$ \\
\hline$-0.650 \mathrm{~V}$ & $7.09 \pm 0.31$ & $2.80 \pm 0.004$ \\
\hline$-0.500 \mathrm{~V}$ & $5.65 \pm 0.61$ & $2.74 \pm 0.005$ \\
\hline$+0.500 \mathrm{~V}$ & $6.18 \pm 0.52$ & $2.73 \pm 0.008$ \\
\hline
\end{tabular}

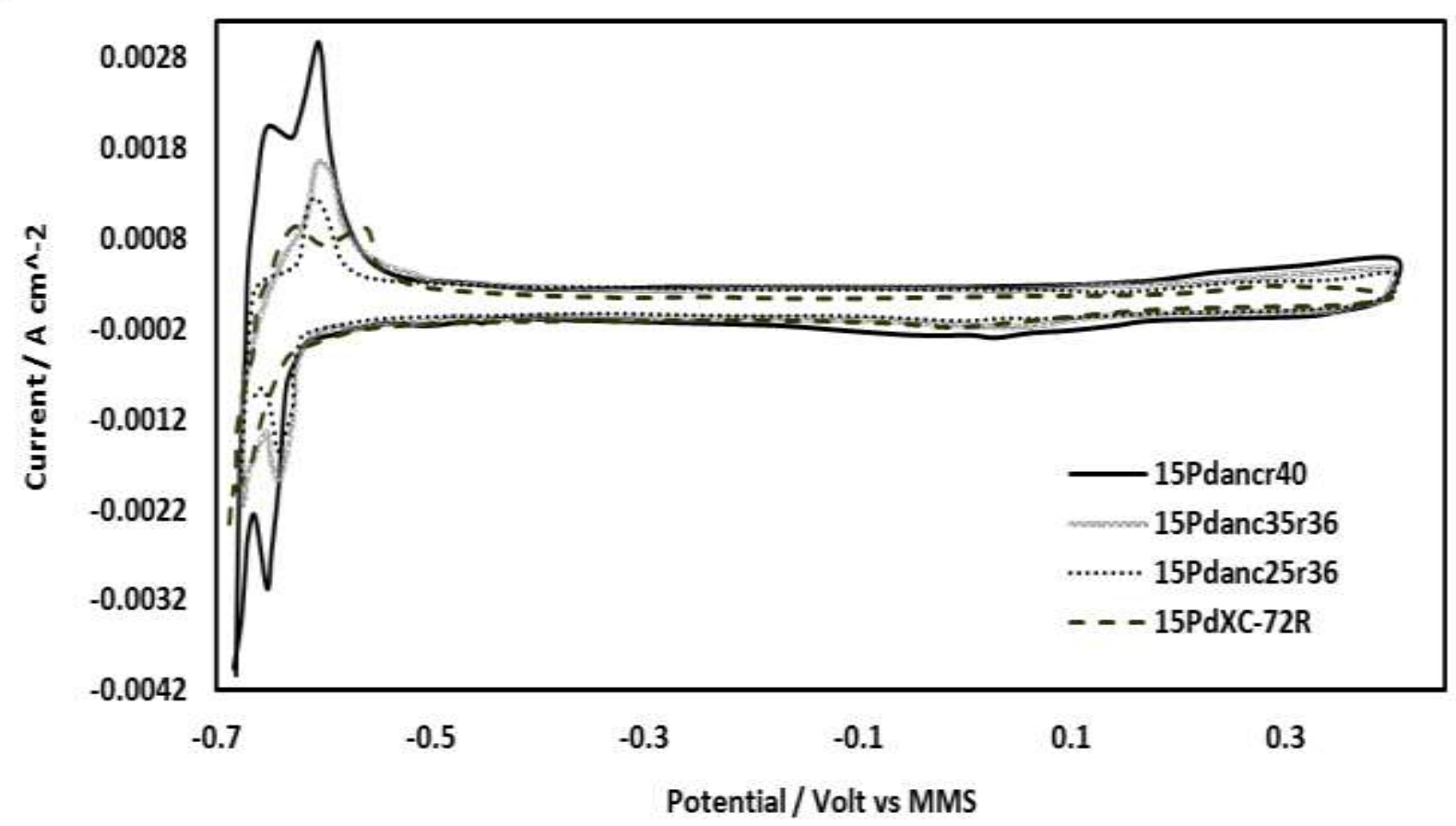

Figure 6. Comparison of $\mathrm{CV}$ measurements to determine the catalyst performance of 15Pdancr40 - calcined and reduced at $400{ }^{\circ} \mathrm{C} ; 15 \mathrm{Pdanc} 35 \mathrm{r} 36$ - calcined at $350{ }^{\circ} \mathrm{C}$ and reduced at $360{ }^{\circ} \mathrm{C} ; 15 \mathrm{Pdanc} 25 \mathrm{r} 36$ - calcined at $250{ }^{\circ} \mathrm{C}$ and reduced at $360^{\circ} \mathrm{C}$, respectively. The $\mathrm{CV}$ was measured at scan rate of $1 \mathrm{mV} \mathrm{s}^{-1}$ in $2.5 \mathrm{~mol} \mathrm{dm}^{-3} \mathrm{H}_{2} \mathrm{SO}_{4}$ at the potential region of $-0.675 \mathrm{~V}$ to $0.4 \mathrm{~V}$ vs MMS reference electrode. 
Abstract ID 23 - International Journal of Hydrogen Energy

\section{Conclusion}

The influence of calcinations and reduction temperature on Pd particle size has been investigated by the ex-situ extended X-ray adsorption fine structure (EXAFS) and Cycle Voltammetry (CV) techniques. The enhancement of electrochemical activity associated with the charger transfer on Pd active surface in the hydride region increases with calcinations and reduction temperature up to $400{ }^{\circ} \mathrm{C}$. No major discrepancy of current change with respect to hydrogen adsorption and desorption peaks was determined for catalyst samples calcined at 250 ${ }^{\circ} \mathrm{C}$ and reduced at $360{ }^{\circ} \mathrm{C}$ (i.e. $15 \mathrm{Pdanc} 25 \mathrm{r} 36$ ) or calcined at $350{ }^{\circ} \mathrm{C}$ and reduced at $360{ }^{\circ} \mathrm{C}$ (i.e. 15Pdanc35r36), respectively. The Pd particle size follows an order of 15 Pdancr40 $(1.0 \mathrm{~nm})>$ 15Pdanc25r36 $(0.9 \mathrm{~nm})>$ 15Pdanc35r36 $(0.8 \mathrm{~nm})$. A high dispersion of small metal particle size is usually correspondent to a high catalyst activity. However, this tendency is not reflected by $\mathrm{CV}$ measurements observed for electrochemical activity of charger transfer in the hydride region, in which the electrocatalytic activity of catalysts is arranged in an order of 15Pdancr40

$>$ 15Pdanc35r36 > 15Pdanc25r36. The Pd location might have played an important role to increase the catalytic activity of Pd particle. For catalyst 15Pdancr40, the majority of Pd atoms are resident at zeolite supercages and/or on the zeolite external surfaces. For those samples made at the calcinations and reduction temperature below $360{ }^{\circ} \mathrm{C}$, the $\mathrm{Pd}$ atoms are most likely to remain at zeolite small cages such as sodalite cages or hexagonal prisms. The mobility of Pd atoms can be facilitated by atomic hydrogen disassociated by $\mathrm{H}_{2}$ molecule or the restoration of zeolite active sites (i.e. Brфnsted acidic sites) during a chemically $\mathrm{H}_{2}$ reduction process.

\section{References}

[1] W. Vielstich, A. Lamm, H.A. Gasteiger, Handbook of Fuel Cell: Fundamentals Technology and Applications, Vol. 1. Fundamental and Survey of Systems, Wiley, ISBN: 978-0-47149926-8, 2003. 
Abstract ID 23 - International Journal of Hydrogen Energy

[2] L. Zhang, Q. Chang, H. Chen, M. Shao, Recent advances in palladium-based electrocatalysts for fuel cell reactions and hydrogen evolution reaction, Nano Energy, 29 (2016), pp. 198-219.

[3] M. Shao, Palladium-based electrocatalysts for hydrogen oxidation and oxygen reduction reactions, J. Power Sources, 196 (2011), pp. 2433-2444.

[4] S. Yao, C. Liu, W. Xing, Enhanced catalytic performance of carbon supported palladium nanoparticles by in-situ synthesis for formic acid electrooxidation, J. Power Sources, 284 (2015), pp. 355-60.

[5] Ghasemi S, Hosseini SR, Nabipour S, Asen P. Palladium nanoparticles supported on grapheme as an efficient electrocatalyst for hydrogen evolution reaction. Int J Hydrogen Energy 2015; 40 (46): 16184-91.

[6] DÖner A, Tezcn F, Kardaas G. Electrocatalytic behavior of the Pd- modified electrocatalyst for hydrogen evolution. Int J Hydrogen Energy 2013; 38 (10): 3881 -8.

[7] Yao, Jun and Yao, Yufeng. Experimental study of characteristics of bimetallic Pt-Fe nanoparticle fuel cell electrocatalyst, Renewable Energy 2015; 81: 182-196.

[8] Ojani R, Raoof JB, Hasheminejad E. One - step electroless deposition of Pd/Pt bimetallic microstructures by galvanic replacement on copper substrate and investigation of its performance for the hydrogen evolution reaction. Int J Hydrogen Energy 2013; 38 (1):92-9.

[9] H. Ramezani, S.N. Azizi, S.R. Hosseini, NaY zeolite as a platform for preparation of Ag nanoparticles arrays in order to construction of $\mathrm{H}_{2} \mathrm{O}_{2}$ sensor, Sensors and Actuators $\mathrm{B}, 248$ (2017), pp. 571-579.

[10] Y.M. Li, Industry Catalysis Principle, 1992. Tian Jing University Publications.

[11] D. Scarano, S. Bordiga, C. Lamberti, G. Ricchiardi, S. Bertarione, G. Spoto, Hydrogen adsorption and spill-over effects on $\mathrm{H}-\mathrm{Y}$ and Pd-containing $\mathrm{Y}$ zeolites: An experimental and theoretical investigation, Applied Catalysis A: General, 307 (2006), pp. 3-12. 
Abstract ID 23 - International Journal of Hydrogen Energy

[12] S.T. Homeyer, W.M.H. Sachtler, Elementary steps in the formation of highly dispersed palladium in NaY: II. Particle formation and growth, J. Catal. 118 (1989), pp. 266-274.

[13] S.T. Homeyer, W.M.H. Sachtler, Elementary steps in the formation of highly dispersed palladium in NaY: I. Pd ion coordination and migration, J. Catal. 117 (1989), pp. 91-101.

[14] G. Bergeret, P. Gallezot, B. Imelik, X-ray study of the activation, reduction, and reoxidation of palladium in Y-type zeolites, J. Phys. Chem. 85 (1981), pp. 411-416.

[15] A. Kleine, P.I. Ryder, N.I. Jaeger, G. Schulz-Eklofff, Electron microscopy of Pt, Pd and Ni particles in a NaX zeolite matrix, Journal of the Chemical Society, Faraday Transactions 1: Physical Chemistry in Condensed Phases, 82 (1986), pp. 205-212.

[16] T. Beutel, Z. Zhang, W.M.H. Sachtler, H. Knozinger, Temperature Dependence of Palladium Cluster Formation in NaY and 5A Zeolites, J. Phys. Chem. 97 (1993), pp. 35793583.

[17] X. Zhao, Y. Hu, L. Liang, C. Liu, J. Liao, W. Xing, Ionic Liquid mediated synthesis of ‘clean' palladium nanoparticles for formic acid electrooxidation, Int. J Hydrogen Energy 37(1) (2012), pp. 51-58.

[18] L.Q. Xu, Z.C. Zhang, B. Marshik, W.M.H. Sachtler, Hydrogen isotope exchange on Pd/NaY and Pd/HY zeolites, Catal. Lett. 10(1-2) (1991), pp. 121-129.

[19] B.E. Conway, B.V. Tilak, Interfacial processes involving electrocatalytic evolution and oxidation of $\mathrm{H}_{2}$, and the role of chemisorbed, H. Electrochem Acta 47(22-23) (2002), pp. 35713594.

[20] J.X. Wang, T.E. Springer, P. Liu, M. Shao, R.R. Adzic, Hydrogen oxidation reaction of Pt in acidic media: adsorption isotherm and activation free energies. J. Phys.Chem. C111(33) (2007) 12425-12433. 
Abstract ID 23 - International Journal of Hydrogen Energy

[21] J. Durst, C. Simon, F. Hasché, H.A. Gasteiger. Hydrogen oxidation and evolution reaction kinetic on carbon supported Pt, Ir, Rh, and Pd Electrocatalysts in Acidic Media. J. Electrochem. Soc. 162(1) (2015) F190-F203.

[22] J. Yao, Y.F. Yao, Investigation of zeolite supported platinum electrocatalyst for electrchemical oxidation of small organics species, Int. J Hydrogen Energy 41(33) (2016), pp. 14747-57.

[23] M.S. Tzou, B.K. Teo, W.M.H. Sachtler, Formation of Pt particles in Y-type zeolites: the influence of co-exchanged metal cations, J. Catal. 113(1) (1988), pp. 220-235.

[24] H.D. Abruna, X-ray absorption spectroscopy in the study of electrochemical system, in: HD Abruna (Eds.), Electrochemical interface: Modern Techniques for In-Situ Interface Characterization, VCH Publishers, New York, 1991, Chapter 1, pp. 1-54.

[25] R.E. Benfield, Mean coordination numbers and the non-metal-metal transition in clusters, J. of the Chemical Society, Faraday Transactions, 88(8) (1992), pp. 1107-1110.

[26] W.M.H. Sachtler, Z.C. Zhang, Zeolite-supported transition metal catalysts, Advances in Catalysis, 39 (1993), pp. 129-220.

[27]. Suarez-Alcantara K, Martinez-Casillas DC, Zheng KB, Zhu Q, Abdellah M Haase D, et al. SEM and XAS characterization at beginning life of Pd-based cathod electrocatalysts in PEM fuel cells. Int J Hydrogen Energy 2014; 39(10): 5358-70.

[28] J. Yao, Y.F. Yao, Zeolite supported palladium nanoparticle characterization for fuel cell application, Int. J Hydrogen Energy, 42(29) (2017), pp. 18560-18567.

[29] Eftekhari A,. Eelectrocatalysts for hydrogen evolution reaction. Int J Hydrogen Energy 2017; 42 (16); 11053-77. 